\title{
Spontaneous resolution of a dissection of the descending aorta after medical treatment with a $\beta$ blocker and a calcium antagonist
}

\author{
TATSUO HOSHINO, MINORU OHMAE, AKIRA SAKAI \\ From the Second Department of Internal Medicine, Kansai Denryoku Hospital, Fukushima-ku, Osaka, Japan
}

SUMMARY A 58 year old man experienced an attack of squeezing chest pain. A contrast enhanced computed tomographic scan showed acute dissection of the descending aorta. Treatment with metoprolol and nicardipine kept his blood pressure below $130 / 90 \mathrm{~mm} \mathrm{Hg}$ while he was supine at rest and after walking. Serial contrast enhanced computed tomographic scans showed opacification of the false lumen (which was not opacified initially) on the 42nd day; moderate regression of the false lumen on the 67th day, and resolution of the false lumen on the 266th day.

This is the first in vivo demonstration of spontaneous resolution of aortic dissection detected by serial contrast enhanced computed tomographic scans.

Healing of an aortic dissection, particularly when thrombosis and organisation have obliterated the dissected segment, is rare and there are only a few necropsy reports of this finding. ${ }^{1}$ Computed tomographic scanning has recently enhanced the rapidity and accuracy of diagnosis of aortic dissection. ${ }^{2-4}$ We report the first case in which spontaneous resolution of the false lumen of aortic dissection was demonstrated in life by serial contrast enhanced computed tomographic scans after medical treatment with a $\beta$ blocker and a calcium antagonist.

\section{Case report}

A 58 year old man suffered from an attack of squeezing chest pain in the morning while he was working in his garden. His blood pressure was 220/180 $\mathrm{mm} \mathrm{Hg}$. A dull chest pain persisted for more than a week after the attack. A contrast enhanced computed tomographic scan on the 13th day disclosed an acute dissection of the descending aorta to a level near the origin of the renal arteries. The false lumen was not opacified (fig 1). A chest $x$ ray showed a wide aortic shadow. The electrocardiogram was normal. Routine laboratory tests were unremarkable except for a high erythrocyte sedimentation rate. He was exam-

Requests for reprints to Dr Tatsuo Hoshino, Second Department of Internal Medicine, Kansai Denryoku Hospital, 2-1-7 Fukushima, Fukushima-ku, Osaka, 553 Japan. ined repeatedly by computed tomographic scans and chest $x$ rays His blood pressure while supine at rest and after walking was maintained below. 130/90 $\mathrm{mm} \mathrm{Hg}$ with metoprolol and nicardipine. He was free from chest pain soon after the start of this treatment. A contrast enhanced computed tomographic scan on the 42nd day showed that the false lumen was opacified to the same degree as the true lumen. Another scan on the 67th day revealed moderate regression of the false lumen. On the 266th day a contrast enhanced computed tomographic scan showed resolution of the false lumen with a thin residual thrombi in the dissected aortic wall (fig 2). A concomitant chest $x$ ray showed that since the initial examination there had been a decrease in the width of the aortic shadow and the thickness of the aortic wall measured from the calcific intima to the outer margin of the aortic shadow. The high erythrocyte sedimentation rate declined gradually over the nine month period. A contrast enhanced computed tomographic scan and a chest $x$ ray were unchanged a year later.

\section{Discussion}

Healing of aortic dissection is usually said to have occurred when the false lumen is endothelialised and communicates with the true lumen at both its origin and termination, forming a so called double aorta. Many cases of such a healing have been found at 

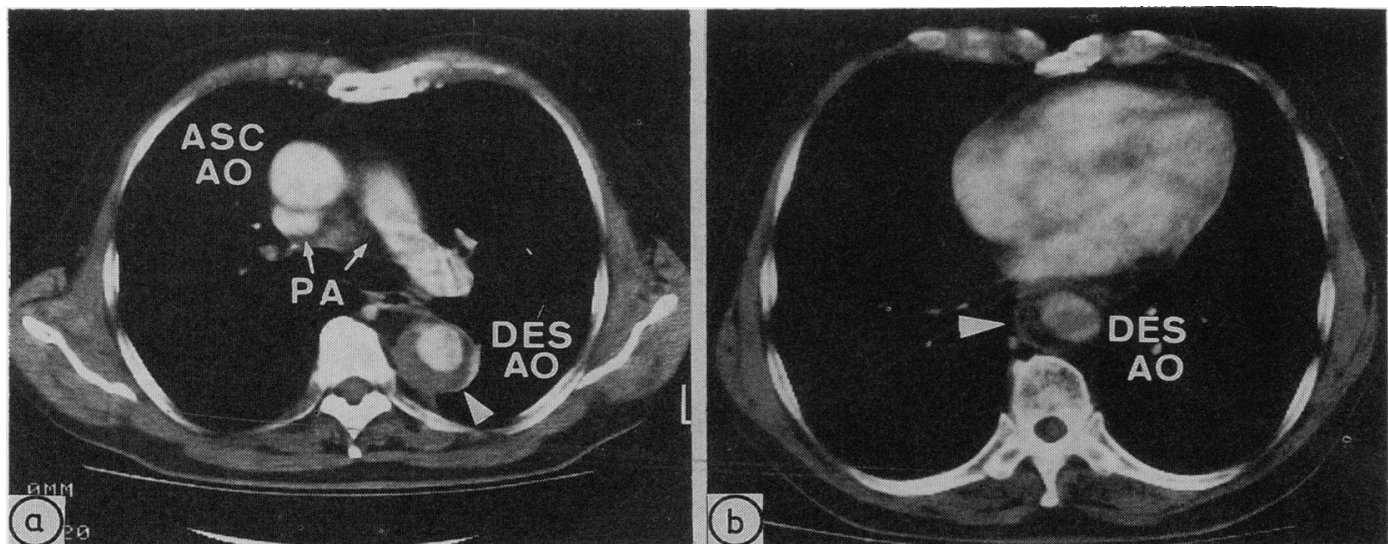

Fig 1 Contrast enhanced computed tomographic scan of the thorax on the 13th day showing acute dissection of the descending aorta. The false lumen is not opacified. (a) Slice imaged at a level near the aortic arch and (b) a slice at a level about $6 \mathrm{~cm}$ below (a). ASC AO, ascending aorta; DES AO, descending aorta; $P A$, pulmonary arteries; arrowhead indicates false lumen.
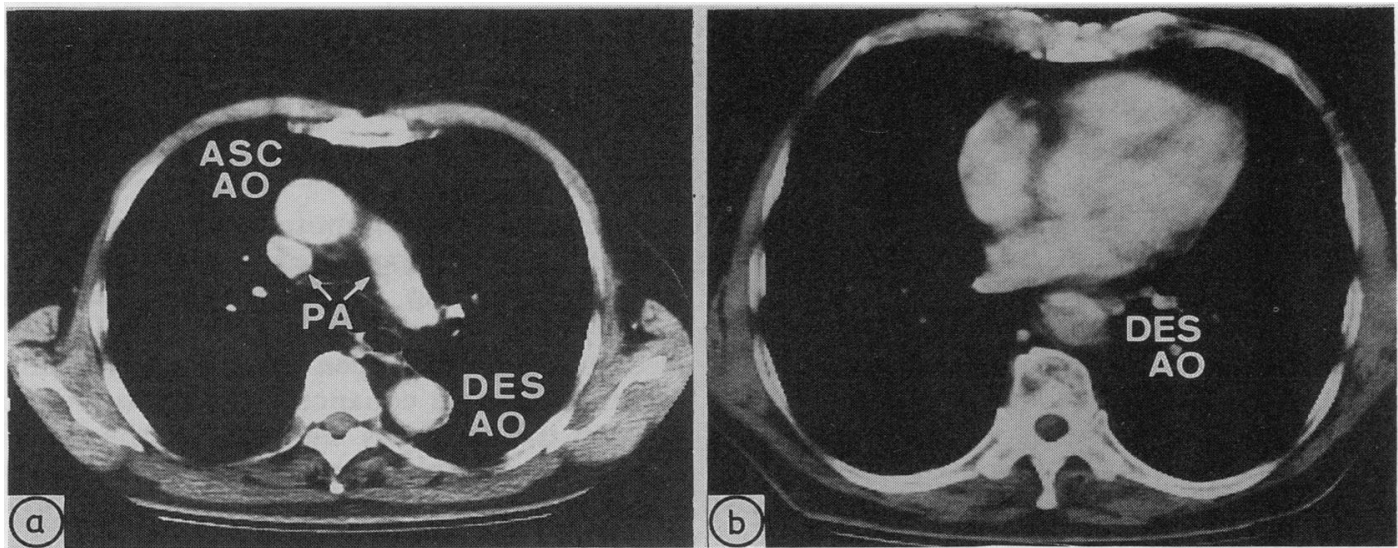

Fig 2 Contrast enhanced computed tomographic scan of the thorax on the 266th day. (a) and (b) are the same views as described in fig 1. Resolution of the false lumen, with thin residual thrombi in the dissected segment, is evident.

necropsy. ${ }^{1}$ Healing produced by obliteration of the dissected segment by thrombosis and organisation is rare; there are only a few reports of this finding at necropsy. ${ }^{56}$ We believe this to be the first in vivo demonstration of the spontaneous resolution of the false lumen of aortic dissection. The resolution was detected by serial contrast enhanced computed tomographic scans. Such scans are a rapid and accurate method of diagnosing aortic dissection ${ }^{2-4}$ and seem to be more suitable than angiography for repeated follow up of patients with aortic dissection.

Medical treatment with a $\beta$ blocker and a vasodilator to maintain blood pressure within normal limits and a suppressed cardiac inotropic state has been advocated in patients with uncomplicated dis? section of the descending aorta. ${ }^{48}$ Maintenance $d 9$ normal and stable blood pressure, which in our case was achieved with a $\beta$ blocker and a calcium antagog nist, seems to have played a major role in the resolub tion of the false lumen. Location of the false lumen may also have had a favourable effect on such a heaf ing. Dissection of the descending thoracic aorta usu ally produces a false lumen behind and to the left of the true lumen, ${ }^{8}$ whereas in this case the false lumeg lay behind and to the right of the true lumen. The spinal column may have acted as a buttress and may have prevented excessive expansion and rupture of the false lumen. 


\section{References}

1 Hirst AE Jr, Johns VJ Jr, Kime SW Jr. Dissecting aneurysm of the aorta: a review of 505 cases. Medicine (Baltimore) 1958;37:217-79.

2 Godwin JD, Herfkens RL, Skiöldebrand CG, Federle MP, Lipton MJ. Evaluation of dissections and aneurysms of the thoracic aorta by conventional and dynamic CT scanning. Radiology 1980;136:125-33.

3 Moncada R, Salinas M, Churchill R, et al. Diagnosis of dissecting aortic aneurysm by computed tomography. Lancet 1981;i:238-41.

4 Miller DC. Acute dissection of the aorta-continuing need for earlier diagnosis and treatment. Mod Concepts Cardiovasc Dis 1985;54:51-5.

5 Shennan T. Completely healed dissecting aneurysm of the aorta with obliteration of the sac. J Pathol 1932;35:161-74.

6 Case records of the Massachusetts General Hospital (Case 41091). N Engl J Med 1955;252:358-64.

7 Doroghazi RM, Slater EE, De Sanctis RW, Buckley MJ, Austen WG, Rosenthal S. Long-term survival of patients with treated aortic dissection. J Am Coll Cardiol 1984;3:1026-34.

8 Wheat MW Jr. Acute dissecting aneurysms of the aorta: diagnosis and treatment-1979. Am Heart $J$ 1980;99:373-87.

\section{Notices}

\section{British Cardiac Society}

The Autumn Meeting will be held at the Wembley Conference Centre, London, on 24 to 26 November 1987 , and the closing date for receipt of abstracts will be 10 July 1987 .

The Annual General Meeting for 1988 will take place in Belfast on 23 and 24 March 1988, and the closing date for receipt of abstracts will be 4 January 1988.

\section{Interventional cardiology}

An International Workshop on Future Directions in Interventional Cardiology, sponsored by the American College of Cardiology, with Santa Barbara Heart and Lung Institute at Goleta Valley Community Hospital, will be held in Santa Barbara on 25 to 27 September 1987. Further information from: Ms Lan Nguyen/1638A, Extramural Programs Department, American College of Cardiology, 9111 Old Georgetown Road, Bethesda, Maryland 20814, USA.

\section{Cardiac Doppler and color flow imaging}

An International Conference on Cardiac Doppler and Color Flow Imaging will be held in Dubrovnik on 29 May to 2 June 1988 . Inquiries to Dr Nikša Drinkovic, Department of Cardiovascular Diseases, University Hospital Centre Rebro, Kišpatićeva 12, 41000 Zagreb, Yugoslavia. 